\title{
Forecast of water level and ice jam thickness using the back propagation neural network and support vector machine methods
}

\author{
${ }^{1}$ J. Wang; ${ }^{2 *} J$. Sui; ${ }^{1}$ L. Guo; ${ }^{3}$ B. W. Karney; ${ }^{4}$ R. Jüpner \\ ${ }^{I}$ School of Civil Engineering, Hefei University of Technology, Anhui Province, China \\ ${ }^{2}$ Environmental Engineering Program, University of Northern British Columbia, 3333 University Way, Prince \\ George, BC, V2N 4V9, Canada \\ ${ }^{3}$ Department of Civil Engineering, University of Toronto, Toronto, Ontario, M5S 1A4, Canada \\ ${ }^{4}$ Institute of Hydraulic Engineering and Water Management, Technical University of Kaiserslautern \\ D-67663 Kaiserslautern, Germany
}

Received 18 November 2009; revised 31 January 2010; accepted 19 February 2010; avaiable online 1 March 2010

\begin{abstract}
Ice jams can sometimes occur in high latitude rivers during winter and the resulting water level rise may generate costly and dangerous flooding such as the recent ice jam flooding in the Nechako River in downtown Prince George in Canada. Thus, the forecast of water level and ice jam thickness is of great importance. This study compares three methods to simulate and forecast water level and ice jam thickness based on field observations of river ice jams in the Quyu Reach of the Yellow River in China. More specifically, simulation results generated by the traditional multivariant regressional method are compared to those of the back propagation neural network and the support vector machine methods. The forecast of ice jam thickness and water level under ice jammed condition have been conducted in two different approaches, 1) simulation of water level and ice jam thickness in the second half of the period of measurement using models developed based on data gained during the first half of the period of measurement, 2) simulation of water level and ice jam thickness at the downstream cross sections using models developed based on data gained at the upstream cross sections. For this reason, as the results of simulation and field observations indicated, the back propagation neural network method and the support vector machine method are superior in terms of accuracy to the multi-variant regressional method.
\end{abstract}

Keywords: Ice jam thickness; Multi-variant regressional method; Water level

\section{INTRODUCTION}

The formation of winter ice cover in northern or high latitude rivers creates a new solid surface and thus directly increases wetted perimeter of flow. Consequently, the resistance of the river reach increases, leading to an increase in water level and/or a decrease in flow velocity (Sui et al., in press). Perhaps even more seriously, ice-cover formation on many rivers is associated with jamming on the reach. Under specific conditions such as with the continuous arrival of frazil ice from the upstream, or when the transported ice is arrested by obstacles such as a stationary ice cover, an ice jam may be formed (Beltaos, 1983; 2000). Due to a large aggregate ice thickness and a high hydraulic resistance relative to the sheet ice, ice jams can result in significant increase in water level and thus cause ice

*Corresponding Author Email: sui@unbc.ca

Tel.: +1 250960 6399; Fax: +1 2509605845 flooding. Such flooding recently occurred on the Nechako River during the winter of 2007 in downtown Prince George, Canada.

In addition to flooding concerns, if an ice jam suddenly clears, the resulting high-velocity surge of water and ice can lead to significant increases in water level that pose a risk to human life and property downstream of the jam. For example, "on February 15, 2003, more than 1,000 residents of Badger, Newfoundland, Canada, were forced to evacuate from their homes when a massive ice jam sparked major flooding from three rivers, leaving their town rapidly encased in ice and water" (Morse and Hicks, 2005). Moreover, the backwater effect of an ice jam on water level increases with the jam thickness. The increase in jam thickness, in turn, increases the channel slope and flow velocity (Sui et al. 2005). 
The most common locations for the formations of ice jam include places with reduced flow velocity. Obvious locations include where the river enters a lake or reservoir, at river bends or when the flow encounters a deep pool. Due to their essential nature, ice problems are invariably complicated. The following are just some factors must be considered in the course of studies of river ice problems:

(a) river morphology, including channel slope, channel geometry, channel networks, shoals, riverbed roughness and vegetation in channel and floodplain;

(b) hydraulic conditions including flow velocities, water depth, water surface profile, influence of downstream;

(c) meteorological factors including air temperature, water temperature, wind speed and snowfall;

(d) many other factors, including things like human interventions and ground heat input.

Gerard and Davar (1995) reviewed the flooding caused by river ice jams across Canada and found that ice jam floods are not only less predictable and sudden, but they are usually accompanied by low temperatures and that massive ice slabs and blocks often move with the floodwaters (Beltaos, 1995; Beltaos et al., 1996; Sui et al., 2002, 2008). It is not surprising that river ice attracts interest of many researchers and engineers in the world (Hicks et al., 1995; Tuthill et al., 1996; Sui et al., 2000; White, 2003; Sui et al., 2005; Bandyopadhyay and Chattopadhyay, 2007). Clearly, the forecast of water levels and ice jam thickness is profoundly important.

Although, it is difficult to precisely simulate a river system under ice covered conditions due to the complexity of a natural river system and the associated meteorological conditions, significant research has been undertaken. Yet because of the inherent danger in measuring ice jam properties and to forecast water level and ice jam thickness, researchers have used a variety of indirect ways to describe ice jam configurations. For example, numerical models are potentially useful and safe tools for determining water levels that may be expected under varying ice jam conditions. McDonald et al. (2002) gave an application that successfully predicted ice jams at a confluence. Grover et al. (1999) predicted water levels in a multichannel river. Mahabir et al. (2006) forecasted the risk of ice jams for Fort McMurray by fuzzy logic. Daly (2002) applied a data modeling approach that incorporated real-time observations for forecasting purposes. DYNARICE (Lu et al., 1999; Shen, 2002) is a coupled Eulerian-Lagrangian model. The hydrodynamics of flow are simulated using a finite-element scheme and the ice dynamics are simulated using a Lagrangian discrete-parcel method. Based on the field observations of water levels and thickness of river ice jams in the Quyu Reach of the Yellow River from 1986 to 1989 , the objective of this study is to forecast water level and ice jam thickness by two new methods, namely, the back propagation neural network method and the support vector machine method. The simulated results by back propagation neural network and support vector machine methods have been compared with those using multi-variant regressional method.

\section{Studied river reach}

Located between $39.6^{\circ} \mathrm{N}$ and $40{ }^{\circ} \mathrm{N}$ latitude and 111 ${ }^{\circ} \mathrm{E}$ and $112^{\circ} \mathrm{E}$ longitude, the Quyu reach (Fig. 1) of the Yellow River in China is $23.9 \mathrm{~km}$ long. The upstream Shiyaobu cross section is located at the Shiyaobu river bend which has a radius of curvature of only $0.7 \mathrm{~km}$. Immediately downstream of the river bend, there is a point bar which in winter is always submerged. Downstream from this point bar, a short open reach is usually maintained by large local flow velocities during winter period. The downstream Shitizi cross section is located about $2 \mathrm{~km}$ upstream of the backwater zone of the Tianqiao reservoir. The Quyu reach is meandering. The channel width ranges from $500 \mathrm{~m}$ to $1000 \mathrm{~m}$. Each year in December, a long open reach in the upstream Inner Mongolia Reach of the Yellow River is exposed to cold air temperatures because of numerous rapids and high flow velocities. This open river reach generates enormous quantities of frazil ice which leads directly the formation of frazil ice jam in the downstream Tianqiao reservoir (dam cross section, no measurements) in December. Due to the impact of the Tianqiao reservoir, an ice jam (Quyu ice jam) will form every year between the Shtizi cross section (backwater cross section) and the Shiyaobu cross section (upstream cross section). As temperatures increase around March, the Quyu ice jam breaks up. As shown in Fig. 1, four measurement cross sections had been set up along the Quyu Reach in winter from 1986 to 1989 to measure water levels, ice jam thickness and thickness of frazil ice accumulated under ice cover. In total, 217 measurements (ice jam thickness and water level) have been conducted along this river reach. Discharges have been measured at the Hequ gaging station. 


\section{MATERIALS AND METHODS}

As mentioned, this study uses three methods to simulate water level and ice jam thickness as a function of the key measured environmental variables. This section reviews the basic methodology and approach for each of these methods.

The multi-variant regressional (MVRE) method

In winter, the water level and ice jam thickness depend on many factors. The obvious and significant factors are effective, including flow velocity, energy slope, channel geometry, features of riverbed (i.e., gradation, grain size and shear velocity), ice discharge from upstream and temperature of air and water. To explore their primary inter-relationships, dimensionless analysis is useful. A non-dimensional water level (or water depth under ice jammed condition) can be described by following function:

$$
\frac{h_{W}}{h_{i}}=f_{1}\left(F_{r}, \frac{h_{f}}{h_{i}}, \frac{T}{T_{a v}}\right)
$$

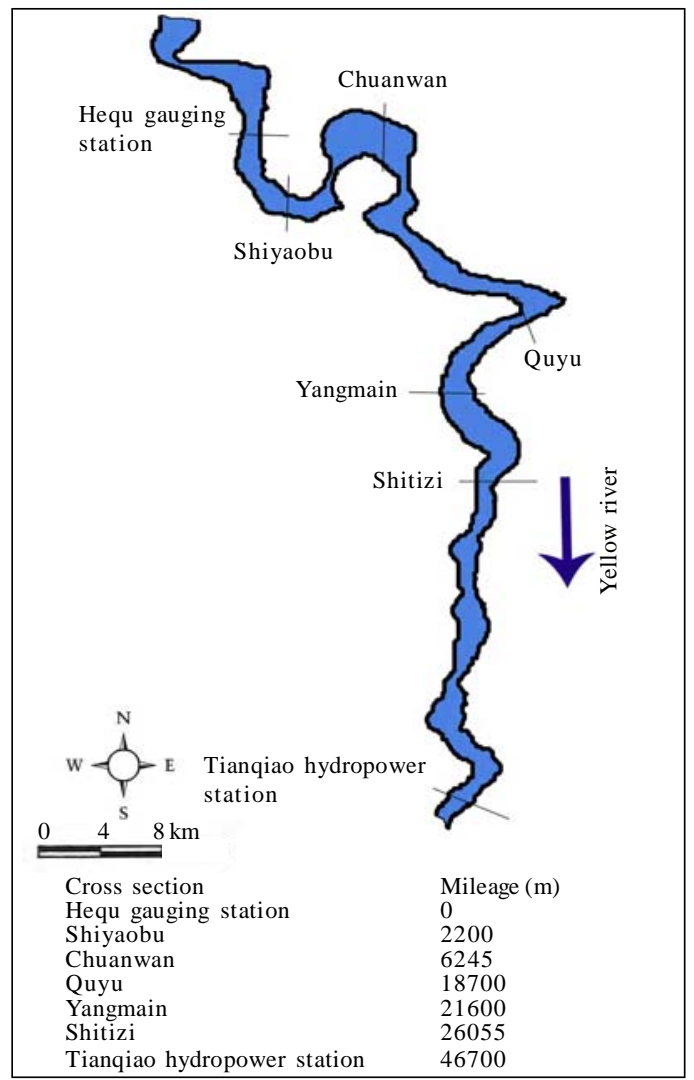

Fig. 1: The schematic map of studied Quyu Reach of the Yellow River in China
Where, $h_{w}=$ water level (or water depth) under ice jammed condition; $h_{i}=$ total ice jam thickness; $h_{f}=$ thickness of frazil accumulated under ice cover; $T=$ air temperature during the calculated period and $T_{a v}=$ long term average air temperature during the calculated period. $F_{r}=v /\left(g h_{w}\right)^{0.5}=$ flow Froude Number under ice jammed condition in which $v=$ average flow velocity and $g$ = gravitational acceleration.

Eq. 1 can be expressed as below:

$$
\frac{h_{w}}{h_{i}}=\varphi_{1}\left(\frac{v}{\sqrt{g h_{w}}}\right)^{a_{1}}\left(\frac{h_{f}}{h_{i}}\right)^{b_{1}}\left(\frac{T}{T_{a v}}\right)^{c_{1}}
$$

Where, $a_{1}, b_{1}$ and $c_{1}$ in Eq. 2 are constants. These constants are different from cross section to cross section.

Eq. 2 can be expressed as linear form of multi-variants as follows,

$$
\begin{aligned}
& \log \left(\frac{h_{W}}{h_{i}}\right)=a_{1} \log \left(\frac{v}{\sqrt{g h_{w}}}\right) \\
& +b_{1} \log \left(\frac{h_{f}}{h_{i}}\right)+c_{1} \log \left(\frac{T}{T_{a v}}\right)+\alpha
\end{aligned}
$$

Similarly, a non-dimensional ice jam thickness can be described by following function:

$$
\frac{h_{i}}{h_{w}}=f_{2}\left(F_{r}, \frac{h_{f}}{h_{w}}, \frac{T}{T_{a v}}\right)
$$

Eq. 4 can also be expressed as:

$$
\frac{h_{i}}{h_{w}}=\varphi_{2}\left(\frac{v}{\sqrt{g h_{w}}}\right)^{a_{2}}\left(\frac{h_{f}}{h_{w}}\right)^{b_{2}}\left(\frac{T}{T_{a v}}\right)^{c_{2}}
$$

Where, $a_{2}, b_{2}$, and $c_{2}$ in Eq. 5 are constants. These constants are different from cross section to cross section.

Eq. 5 can be expressed as linear form of multi-variants as:

$$
\begin{aligned}
& \log \left(\frac{h_{i}}{h_{w}}\right)=a_{2} \log \left(\frac{v}{\sqrt{g h_{w}}}\right) \\
& +b_{2} \log \left(\frac{h_{f}}{h_{w}}\right)+c_{2} \log \left(\frac{T}{T_{a v}}\right)+\beta
\end{aligned}
$$

The support vector machine (SVM) method

The SVM has shown a great potential in numerous visual learning and pattern recognition problems. A 
SVM is a learning algorithm for pattern classification and regression (Vapnik, 1995; Vapnik, et al., 1997; Smola and Schoelkopf, 2004). In SVM analysis, the basic idea is to map original data into a feature space with higher dimensionality via a non-linear mapping function, which is usually unknown and then carry on linear regression in the feature space. Therefore, the regression approximation addresses a problem of estimating a function based on a given data set. The expected classification error of unseen test samples can be minimized.

The SVM method approximates the function in the following form,

$y \quad \sum_{i}^{n} w_{i} \phi_{i}(x)+b$

Where $x=$ original data; $\phi=$ a non-linear mapping function; $\left\{\phi_{i}(x)\right\}_{i_{1}}^{n}$ represents the input features and $\left\{w_{i}\right\}_{i 1}^{n}$ and $b$ are coefficients. These are estimated by minimizing the regularized risk function by following equation:

$R(C) \quad \frac{C}{N} \sum_{i=1}^{N} L_{\beta}\left(d_{i}, y_{i}\right)+\frac{\|w\|^{2}}{2}$
with $\quad L_{\beta}(d, y) \quad\left\{\begin{array}{ll}|d-y|-\beta, & \text { if }|d-y| \geq \beta \\ 0 & \text { others }\end{array}\right\}$

Where, $\beta=$ a prescribed parameter, normally specified as $0.001 ; L_{\beta}(d, y)=\beta$-insensitive loss function which does not penalize errors less than $\beta$; $\|\mathrm{w}\|^{2} / 2$ is used to assess the flatness. $C=$ coefficient determining the trade-off between the training error and the model flatness, normally specified as 100 .

Slack variables can be introduced into Eq. 7 and 8 to convert them to a constrained form. The SVM method can be applied in various ways including to achieve the regression approximation, the estimation of the probability density function and for other steps.

The back propagation neural network (BP-NN) method

The neural network (NN) is a group of (artificial) neurons connected together. Connecting neurons to form a NN can be done in various ways. NNs have the ability to learn by example. That is, a learning set that consists of some input examples and the known-correct output for each case must be provided. Therefore, these input-output examples are applied to show the network what type of behavior is expected and the back propagation (BP) algorithm allows the network to adapt. NNs have been used in many commercial applications like character recognition, image recognition, credit evaluation, fraud detection and stock forecasting. In the late 1980's, interest in NN increased with algorithms like BP-NN which is one of the popular NNs, as shown in Fig. 2. As pointed out by Crochat and Franklin (2000), the mathematical analysis of such networks is much more complex.

In the currently application, attentions have been restricted to the simplest variety of neural network, known as a multilayer perception. This NN consists of only an input layer; hidden layer and output layer. As summarized by Habra (2005), some important features of the BP-NN can be described as following: 1) each neuron has its own input weights; 2) the weights for the input layer are assumed to be 1 for each input, namely, input values are not changed; 3 ) the output of a neuron in a layer goes to all neurons in the following layer; 4) the output of the NN is reached by applying input values to the input layer, passing the output of each neuron to the following layer as input and 5) the BP- NN must have at least an input layer and an output layer. It could have zero or more hidden layers. The BP-NN works in two modes. The supervised training mode is the one widely used. The training can be summarized as follows: 1) start by initializing the input weights for all neurons to some random numbers between 0 and 1 ; 2) apply input to the network; 2) calculate the output; 3 ) compare the resulting output with the desired output for the given input (this is

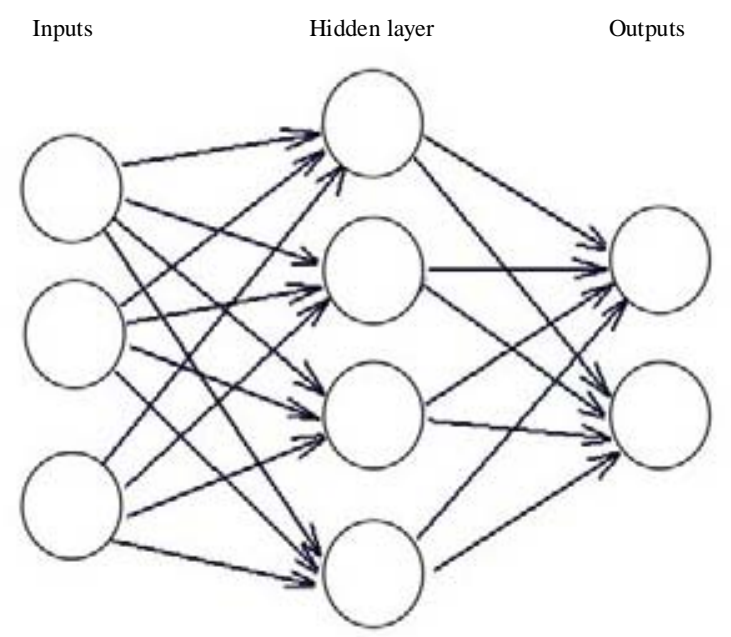

Fig. 2: The diagram shows a back propagation neural network 
called the error); 4) modify the weights and threshold for all neurons using the error; 5) repeat the process until error reaches an acceptable value, which means that the NN was trained successfully (in case of reaching a maximum count of iterations, which means that the NN training was not successful). The artificial neural network, has shown potential for modeling the behavior of complex nonlinear processes such as those associated with river ice jams. In the last couple of years, researchers have used neural network method to assess river ice process. As pointed by Massie et al. (2001), when the BP-NN method is used to simulated river ice process, the selection of input variables is perhaps the most critical decision that will impact on mapping accuracy in a neural network. Massie et al. (2001) explored the viability of neural networks, black-box models that can be 'trained' to represent complex non-linear cause-effect relationships accurately. Using BP-NN method, they predicted breakup ice jams at Oil City, Pennsylvania. They claimed that, with all the original data, the network produced $94 \%$ jam accuracy and $93 \%$ no jam accuracy. Using data from the Athabasca River Basin, Mahabir et al. (2006) used both fuzzy and neuro-fuzzy expert systems to successfully product the severity of water levels associated with the spring breakup. In this study, the BP-NN method, SVM method and MVRE method have been used in forecasting of water level and ice jam thickness, based on the data set measured during winter from 1987 to 1989 for the Quyu ice jam of the Yellow River.

\section{RESULTS AND DISCUSSION}

Forecast of water level

The data set measured at the Chuanwan cross section (73 measurements), Quyu cross section (72 measurements) and Yangmian (72 measurements) cross section included many key terms: water level, ice jam thickness (thickness of frazil accumulation under ice cover and thickness of ice cover). Discharges were available at the upstream Hequ gauging station. Based on discharge and water depth under the ice cover, the average flow velocity was estimated. Air temperatures were measured at the Hequ climate station.

Forecasted water level using the first half of the measurements

According to Eq. 1, dimensionless variables were determined using the data obtained during the first half of the period of measurement at each cross section. The SPSS statistical software has been used to generate the coefficients in the multi-variant regressional equation based on this data set (including, water depth, discharge, ice jam thickness, thickness of frazil accumulation under ice cover and air temperature). Then, to predict water level (water depth) under ice jammed condition during the second half of the period of measurement, following data gained during the second half of the period of measurement at each cross section were used: discharge, ice jam thickness, thickness of frazil accumulation under ice cover and air temperature.

Using and modifying the MATLAB software package, models have developed based on the SVM and BP-NN methods. Following data gained during the first half of the period of measurement at each cross section have been used for the development of the models: water depth, discharge, ice jam thickness, thickness of frazil accumulation under ice cover and air temperature. This data set has been used as the training samples and applied as the inputs in the networks to calculate the outputs. The outputs have been compared with the measured data. Once the neural network training was successful, then, the trained mode is used to forecast water level using data (including discharge, ice jam thickness, thickness of frazil accumulation under ice cover and air temperature) gained during the second half of the period of measurement. The forecast of water levels at each cross section have been carried out by using MVRE, SVM and BP-NN methods. The simulated results from these three methods are compared, in Table 1 and shown in Figs. 3a-c. Table 1 indicates that, within a tolerable range of relative error of $5 \%$, the ratio of the forecasted water level to the measured water level using SVM and BP-NN methods is $55 \%$ and $51 \%$, respectively. Within an allowed relative error of $15 \%$, by using SVM and BP-NN methods, the ratio of the forecasted water level to the water level measured is $96 \%$ and $94 \%$, respectively.

If the relative error criterion is relaxed to $20 \%$, determined by using SVM, BP-NN and MVRE methods, the ratio of the forecasted water level to the measured water level is as $98 \%, 97 \%$ and $60 \%$, respectively.

As shown in Figs. 3a-c , by both SVM and BP-NN methods, the deviations of the calculated water levels from the measured water levels are obviously less than those measured by the MVRE method. Clearly, both SVM and BP-NN methods can be used to forecast water 
Table 1: Forecasted water depths and ice jam thicknesses using models developed through SVM, BP-NN and MVRE methods (simulation based on data gained during the first half of the period of measurement)

\begin{tabular}{|c|c|c|c|c|c|c|c|c|c|c|c|c|c|c|c|c|}
\hline \multirow{3}{*}{$\begin{array}{l}\text { Simulation methods } \\
\text { Error range }(\%)\end{array}$} & \multicolumn{8}{|c|}{ Water depth } & \multicolumn{8}{|c|}{ Ice jam thickness } \\
\hline & \multicolumn{3}{|c|}{ SVM } & \multicolumn{3}{|c|}{ BP-NN } & \multicolumn{2}{|c|}{ MVRE } & \multicolumn{3}{|c|}{ SVM } & \multicolumn{3}{|c|}{ BP-NN } & \multicolumn{2}{|c|}{ MVRE } \\
\hline & $<5$ & $<15$ & $<20$ & $<5$ & $<15$ & $<20$ & $<20$ & $>20$ & $<5$ & $<15$ & $<20$ & $<5$ & $<15$ & $<20$ & $<20$ & $>20$ \\
\hline $\begin{array}{l}\text { Ratio of forecasted value to } \\
\text { measured value }(\%)\end{array}$ & 55 & 96 & 98.3 & 51 & 94 & 96.9 & 59.7 & 40.3 & 30 & 87 & 89 & 37 & 87 & 91 & 52 & 48 \\
\hline
\end{tabular}
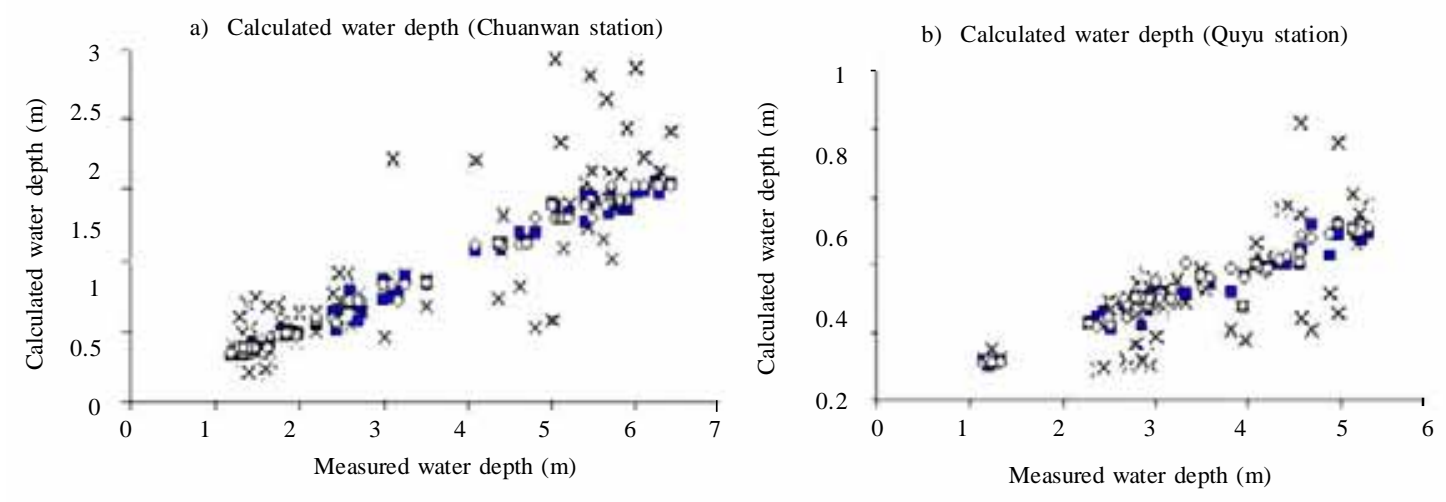

c) Calculated water depth (Yangmian station) d) Calculated water depth
(from upstream to downstream)
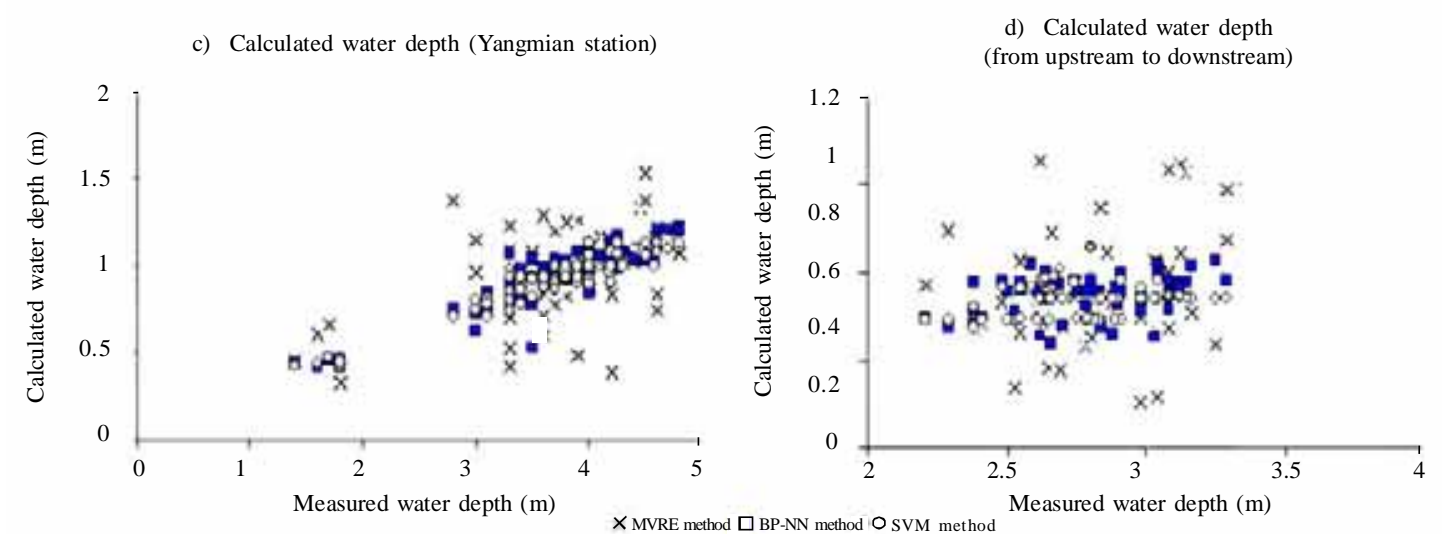

Fig. 3: Comparison of the forecasted water depths with measured water depths under ice jammed condition by using three different methods

level under ice jammed condition and generate good results, comparing to the results by MVRE method.

\section{Forecast of water level based on data gained at the upstream cross sections}

In practice, it is important to forecast water level under ice jammed condition at the downstream cross section using measured data at the upstream cross sections such as water level, discharge, ice jam thickness, thickness of frazil ice accumulated under ice cover and air temperature. In the regression method, dimensionless variables were determined from data gained at the upstream cross section. Then, the SPSS statistical software generated the coefficients in the multivariant regressional equation based on this data set gained at the upstream cross section, such as, water depth, discharge, ice jam thickness, thickness of frazil accumulation under ice cover and air temperature. Then, the multi-regressional equation derived from data measured at the upstream cross section is used to forecast water level under ice jammed condition at the downstream cross section. Using and modifying the MATLAB software package, models have been developed based on the SVM and BP-NN methods to predict water level under ice jammed condition at the downstream cross section. Data obtained at the upstream cross section 
were used for the development of the models: water level, discharge, ice jam thickness, thickness of frazil accumulation under ice cover and air temperature. This data set has been used as the training sample and applied as the inputs in the networks to calculate the outputs. Once the neural network training was completed, the trained modes are used to forecast water level at the downstream cross section. The predicted water levels at the downstream cross sections have been compared using these three methods as shown in Table 2 and Fig. 3d. Within a tolerable range of relative error of $5 \%$, the ratio of the forecasted water level to the measured water level by using SVM and BP-NN methods is $29 \%$ and $44 \%$, respectively. When the relative error was allowed to be $15 \%$ or less, the ratio of the forecasted water level to the measured water level using SVM and BP-NN methods is $89 \%$ and 88 $\%$, respectively. For a relative error of $20 \%$, the ratio of the forecasted water level to the measured water level using SVM, BP-NN and MVRE methods is $95 \%, 96 \%$ and $62 \%$, respectively. As Fig. 3d shows, the deviations of the predicted water levels are clearly lower by both SVM and BP-NN methods than the MVRE method.

Thus, both SVM and BP-NN methods forecasted water level under ice jammed condition more accurately than the MVRE method.

\section{Forecast of ice jam thickness}

In practice, the forecast of ice jam thickness is very important for flood protection and operation of hydropower stations. Additionally, significant riverbed scour normally occurs under ice jammed conditions, with scour increasing along with the quantity of the ice accumulation (Sui et al., 2006, 2007; Wang et al., 2008; 2009). Conceptually, the growth and diminishing of an ice jam have been mainly affected by thermodynamic and hydraulic factors, such as air temperature, water temperature, discharge and water level.
Forecasting ice jam thickness using the first half of the measurements

According to Eq. 4, a model used to predict the dimensionless ice jam thickness has been developed at first based on data gained during the first half of the period of measurement at each cross section. The SPSS statistical software was again used to generate the coefficients in the multi-variant regressional equation based on this data set (water depth, discharge, ice jam thickness, thickness of frazil accumulation under ice cover and air temperature). Then, to forecast ice jam thickness, data gained during the second half of the period of measurement (including discharge, water level and air temperature) was again used at each cross section. Using and modifying the MATLAB software package, models have developed to forecast ice jam thickness based on the SVM and BP-NN methods. Following data gained during the first half of the period of measurement at each cross section have been used for the development of the models. This data set was used as the training samples and applied as the inputs in the network to calculate ice jam thickness. The calculated ice jam thicknesses have been compared with the measured data. Once the neural network training was completed, the trained mode is used to forecast ice jam thickness using some data, including discharge, water level under ice-covered condition and air temperature gained during the second half of the period of measurement.

All three methods were used to predict ice jam thicknesses at each cross section. Table 1 and Figs. $4 \mathrm{a}-\mathrm{c}$ show the deviations of forecasted jam thicknesses from the measured jam thicknesses. As Table 1 indicates, within a tolerable range of relative error of $5 \%$, the ratio of the forecasted jam thickness to the measured jam thickness by using SVM and BP-NN methods is 30 $\%$ and $37 \%$, respectively. For a relative error of $15 \%$, the ratio of the forecasted jam thickness to the measured jam thickness by SVM and BP-NN methods is $87 \%$ and $87 \%$, respectively. Within a tolerable range of relative error of $20 \%$, the ratio of the forecasted jam

Table 2: Forecasted water depths and ice jam thicknesses using models developed through SVM, BP-NN and MVRE methods (simulation is based on data gained at the upstream cross section)

\begin{tabular}{|c|c|c|c|c|c|c|c|c|c|c|c|c|c|c|c|c|}
\hline \multirow{3}{*}{$\begin{array}{l}\text { Simulation methods } \\
\text { Error range }(\%)\end{array}$} & \multicolumn{8}{|c|}{ Water depth } & \multicolumn{8}{|c|}{ Ice jam thickness } \\
\hline & \multicolumn{3}{|c|}{ SVM } & \multicolumn{3}{|c|}{ BP-NN } & \multicolumn{2}{|c|}{ MVRE } & \multicolumn{3}{|c|}{ SVM } & \multicolumn{3}{|c|}{ BP-NN } & \multicolumn{2}{|c|}{ MVRE } \\
\hline & $<5$ & $<15$ & $<20$ & $<5$ & $<15$ & $<20$ & $<20$ & $>20$ & $<5$ & $<15$ & $<20$ & $<5$ & $<15$ & $<20$ & $<20$ & $>20$ \\
\hline $\begin{array}{l}\text { Ratio of forecasted value to } \\
\text { measured value }(\%)\end{array}$ & 29 & 89 & 95 & 44 & 88 & 96 & 62 & 38 & 29 & 62 & 86 & 16 & 58 & 79 & 62 & 38 \\
\hline
\end{tabular}


thickness to the measured jam thickness by SVM, BP$\mathrm{NN}$ and MVRE methods is $89 \%, 91 \%$ and $52 \%$, respectively. As Figs. 4a-c shown, the deviations of the predicted jam thicknesses from the measured jam thicknesses by both SVM and BP-NN methods are obviously less than those by the MVRE method. Clearly, both SVM and BP-NN methods can be used to forecast jam thickness and generate good results, comparing to the results obtained using MVRE method.

\section{Forecast of jam thickness based on data gained at the upstream cross sections}

Similarly to the forecast of water level under ice jammed condition by measured data from the upstream cross sections, jam thickness could also be predicted using models developed based on data measured at the upstream cross section. Regression models can predict the dimensionless ice jam thickness through dimensionless variables obtained at the upstream cross section. The SPSS statistical software can then generate the coefficients in the multi-variant regressional equation
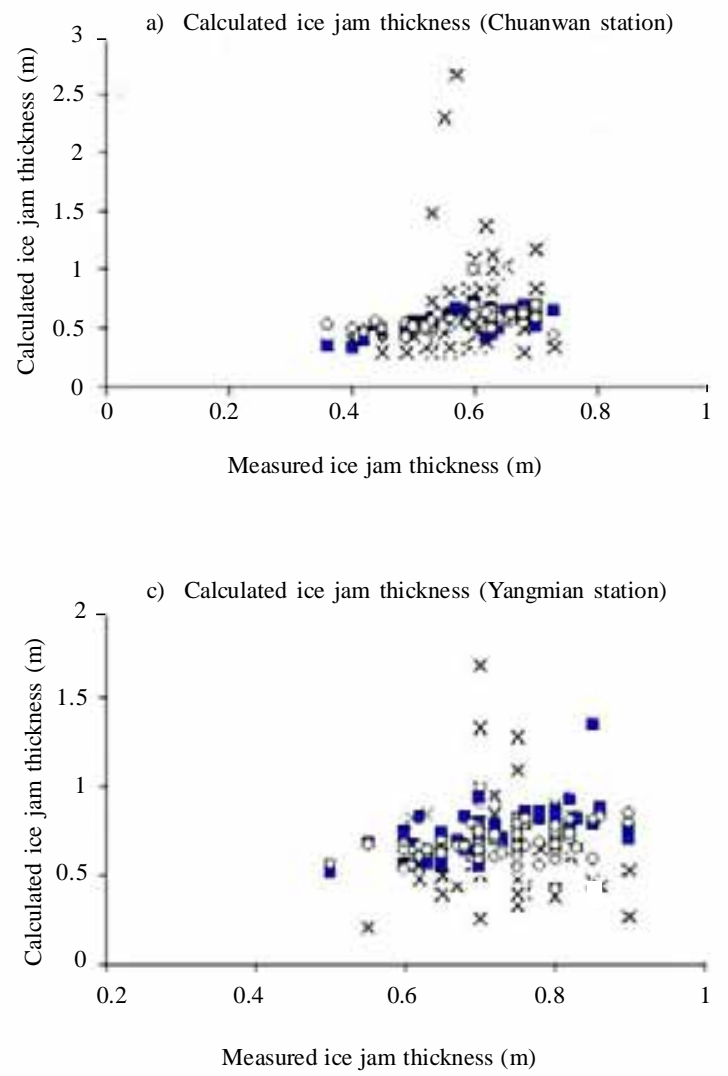

based on this data set gained at the upstream cross section, such as water depth, discharge, ice jam thickness, thickness of frazil accumulation under ice cover and air temperature. Then, the multi-regressional equation derived from the upstream cross section is used to forecast jam thickness at the downstream cross section. To predict jam thickness at the downstream cross section, using and modifying the MATLAB software package, models have been developed based on the SVM and BP-NN methods. Following data gained at the upstream cross section have been used for the development of the models: water level, discharge, ice jam thickness, thickness of frazil accumulation under ice cover and air temperature. This data set has been used as the training samples and applied as the inputs in the networks to calculate jam thicknesses. Once the neural network training was successful, the trained mode is used to forecast jam thicknesses at the downstream cross section. The predicted jam thicknesses at the downstream cross sections using these three methods have been compared, as shown in Table 2 and Fig. $4 \mathrm{~d}$.
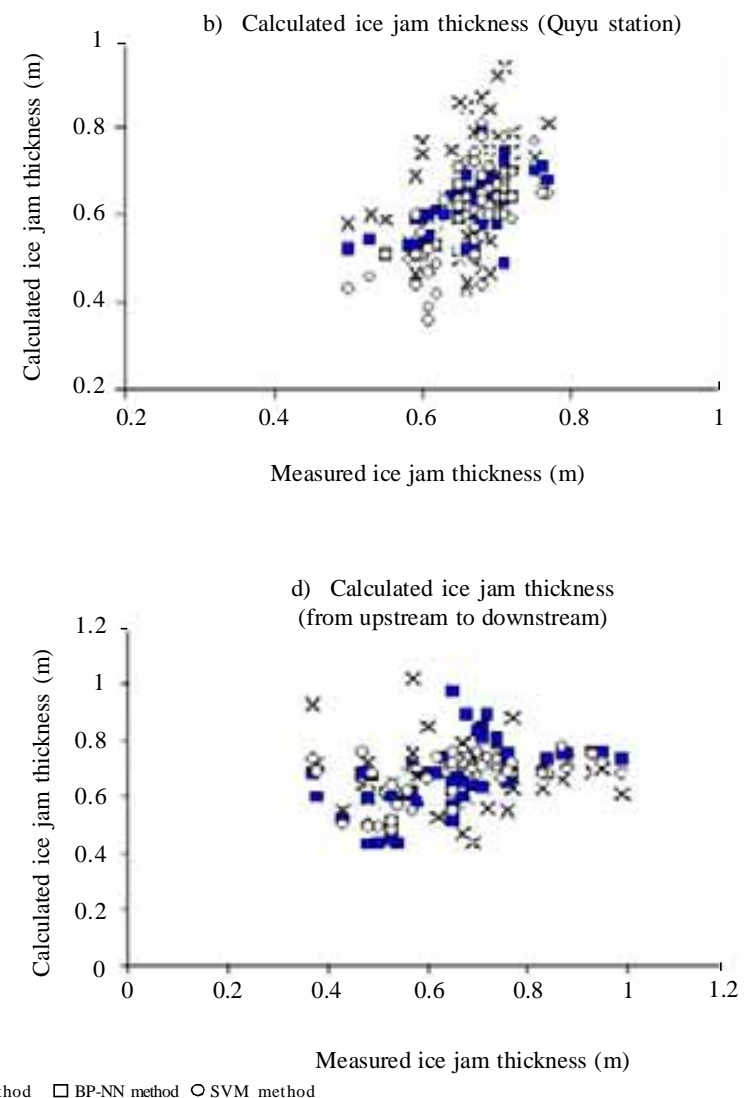

$\times$ MVRE method $\square$ BP-NN method O SVM method

Fig. 4: Comparison of the forecasted ice jam thicknesses with measured ice jam thicknesses by using three different methods 
Within a tolerable range of relative error of $5 \%$, the ratio of the forecasted jam thickness to the measured jam thickness by using SVM and BP-NN methods is 29 $\%$ and $16 \%$ respectively. For a maximum allowed error of $15 \%$, the ratio of the forecasted jam thickness to the measured jam thickness by using SVM and BP-NN methods is $62 \%$ and $58 \%$, respectively. For a relative error of $20 \%$, the ratio of the forecasted jam thickness to the measured jam thickness using SVM, BP-NN and MVRE methods is $86 \%, 79 \%$ and $62 \%$, respectively. As Fig. 4d shown, the deviations of the predicted jam thicknesses from the measured jam thicknesses by using both SVM and BP-NN methods are obviously less than those by using the MVRE method. Overall, using these three methods, the results (both water level and jam thickness) forecasted using models developed based on data measured at the upstream cross section deviate clearly more compared to those determined by models developed based on data gained during the first half of the period of measurement. This may be resulted from the complexity of the natural channel, such as deformation of riverbed, etc. One can say that the MVRE method should not be used to predict water level and jam thickness. Both the SVM and the BP-NN methods can be used to forecast water level and jam thickness and generate good results.

\section{CONCLUSION}

In this research, based on field observations on Quyu ice jams of the Yellow River, the BP-NN method and the SVM method have been used to predict ice jam thickness and water level under ice jammed condition. The simulation results generated from the BP-NN and SVM methods have been compared with the results by a MVRE model. The forecast of ice jam thickness and water level under ice jammed condition have been conducted in two different approaches, 1) simulation of water level and ice jam thickness in the second half of the period of measurement using models developed based on data gained during the first half of the period of measurement, 2) simulation of water level and ice jam thickness at the downstream cross sections using models developed based on data gained at the upstream cross sections.

It is found that the simulations at each cross section using models developed based on data gained during the first half of the period of measurement provide a better results than those developed based on data gained at the upstream cross sections. It is noticed that the simulations using models developed through both SVM and BP-NN methods clearly give better results than those developed through the MVRE method. For the investigated cases, within a tolerable range of relative error of $20 \%$, the simulations of water level and ice jam thickness in the second half of the period of measurement using models developed based on data gained during the first half of the period of measurement are given as following:

- The ratio of the forecasted water level to the measured water level using SVM, BP-NN and MVRE methods is $98 \%, 97 \%$ and $60 \%$, respectively;

- The ratio of the forecasted jam thickness to the measured jam thickness by SVM, BP-NN and MVRE methods is $89 \%, 91 \%$ and $52 \%$, respectively.

Within a tolerable range of relative error of $20 \%$, simulation of water level and ice jam thickness at the downstream cross sections by using models developed based on data gained at the upstream cross sections are examplewise given as follows:

- The ratio of the forecasted water level to the measured water level by SVM, BP-NN and MVRE methods is $95 \%, 96 \%$ and $62 \%$, respectively;

- The ratio of the forecasted jam thickness to the measured jam thickness using SVM, BP-NN and MVRE methods is $86 \%, 79 \%$ and $62 \%$, respectively.

Overall, both the SVM and the BP-NN methods can be used to forecast water level and jam thickness. The prediction of the forecasted results from the measured results using both SVM and BP-NN methods is much more accurate than that obtained through the MVRE method.

\section{ACKNOWLEDGMENTS}

The authors would like to acknowledge that this research work is financially supported by the National Natural Science Foundation of China (Grant number: 50979021), Natural Science Foundation of Anhui Province (Grant number: 090415217) and and Hefei University of Technology (GDBJ2008-020-Seed Grant for Ph.D.)

\section{REFERENCES}

Bandyopadhyay, G.; Chattopadhyay, S., (2007). Single hidden layer artificial neural network models versus multiple linear regression model in forecasting the time series of total ozone. Int. J. Environ. Sci. Tech., 4 (1), 141-150 (10 pages)

Beltaos, S., (1983). River ice jam: Theory, case studies and application. ASCE J. Hydraulic Eng., 109 (10), 1338-1359 (22 pages).

Beltaos, S. (Ed.), (1995). River ice jams. Water Resources Publications, Littleton, Colorado, USA. 
Beltaos, S., (2000). Advances in river ice hydrology. Hydro. Processes, 14 (9), 1613-1625 (13 pages).

Beltaos, S.; Burrell, B.; Ismail, S., (1996). 1991 ice jamming along the Saint John River: A case study. Can. J. Civil Eng., 23 (2), 381-394 (14 pages).

Crochat, P.; Franklin, D., (2000). Back-propagation neural network tutorial, Available on, http://ieee.uow.edu.au/ daniel/

Daly, S. F., (2002). Data assimilation in river ice forecasting. Proceedings of the IAHR the $16^{\text {th. }}$ International Symposium on Ice, Dunedin, New Zealand, 1, 204-210 (7 pages).

Gerard, R. L.; Davar, K. S., (1995), Chapter 1: Introduction in "In river ice jams". S. Beltaos (Ed.), Water Resources Publications, Littleton, Colorado, USA, 1-28.

Grover, P.; Vrkljan, C.; Beltaos, S.; Andres, D., (1999). Prediction of ice jam water levels in a multi-channel river: Fort Albany, Ontario. Proceedings of the $10^{\text {th. }}$ Workshop on River Ice, Edmonton, Canada, 15-29.

Habra, A., (2005). Neural networks - an introduction, Available on http://www.tek271.com/articles/neuralNet/IntoToNeural Nets.html.

Hicks, F.; Chen, X.; Andres, D., (1995). Effects of ice on the hydraulics of Mackenzie River at the outlet of Great Slave Lake, N.W.T.: A case study. Can. J. Civil Eng., 22 (1), 43-54 (12 pages).

Lu, S.; Shen, H. T.; Crissman, R. D., (1999). Numerical study of ice jam dynamics in upper Niagara river. ASCE J. C. Eng., 13 (2), 78-102 (25 pages).

Mahabir, C.; Hicks, F.; Fayek, R., (2006). Neuro-fuzzy river ice breakup forecasting system. J. Cold Reg. Sci. Tech., 46 (2), 100-112 (13 pages)

Massie, D. D.; White, K. D.; Daly. S. F.; Soofi, A., (2001). Predicting ice jams using neural networks. Proceedings of the $11^{\text {th. }}$ Workshop on River Ice. Ottawa. 209-216.

McDonald, R.; White, K. D.; Daly, S.; Massie, D. D., (2002). Implementation of an ice jam predictor with user interface. Proceedings of the $16^{\text {th. }}$ IAHR International Symposium on Ice, Dunedin, New Zealand. 1, 220-227.

Morse, B.; Hicks, F., (2005). Advances in river ice hydrology 1999-2003, Hydro. Processes, 19 (1), 247-263 (17 pages).

Shen, H. T., (2002). Development of a comprehensive river ice simulation system. Proceedings of the $16^{\text {th. }}$ IAHR International Symposium on Ice, Dunedin. New Zealand. $1,142-148$.
Smola, A. J.; Schoelkopf, B. A., (2004). Tutorial on support vector regression. Stat. Comput., 14 (3), 199-222 (24 pages).

Sui, J.; Hicks, F.; Menounos, B., (2006). Observations of riverbed scour under a developing hanging ice dam. Can. J. Civil Eng., 33 (2), 214-218 (5 pages).

Sui, J.; Karney, B.; Fang, D., (2005). Variation in water level under ice-jammed condition-field investigation and experimental study. Nord. Hydrol., 36 (1), 65-84 (20 pages)

Sui, J.; Karney, B.; Sun, Z.; Wang, D.. (2002). Field investigation of frazil jam evolution-a case study. ASCE J. Hydraulic Eng., 128 (8), 781-787 (7 pages).

Sui, J.; Thring, R.; Karney, B.; Wang, J., (2007). Effects of river ice on stage-discharge relationships-a case study of the Yellow River. Int. J. Sediment. Res., 22 (4), 263 - 272 (10 pages).

Sui, J.; Wang, J.; He, Y.; Krol, F., (in press). Velocity profiles and incipient motion of frazil particles under ice cover. Int. J. Sediment Res.

Sui, J.; Wang, D.; Karney, B. W., (2000). Sediment concentration and deformation of riverbed in a frazil jammed river reach. Can. J. Civil Eng., 27 (6), 1120-1129 (10 pages).

Sui, J.; Wang, J.; Balachandar, R.; Sun, Z.; Wang, D., (2008). Accumulation of frazil ice along a river bend. Can. J. Civil Eng., 35 (2), 158-169 (12 pages).

Tuthill, A. M.; Wuebben, J. L.; Daly, S. F.; White, K. D., (1996). Probability distribution for peak stage on river affected by ice jams. ASCE J. Cold Reg. Eng., 10 (1), 36-57 (22 pages).

Vapnik, V., (1995). The nature of statistical learning theory. Springer-Verlag, New York.

Vapnik, V.; Golowich, S.; Smola, A., (1997). Support method for function approximation regression estimation, and signal processing. In: Advance in neural information processing system 9, Mozer, M.; Jordan, M.; Petsche, T. (Eds.), MIT Press, Cambridge, MA.

Wang, J.; Sui, J.; Chen, P., (2009). Numerical simulations of ice accumulation under ice cover along a river bend. Int. J. Environ. Sci. Tech., 6 (1) 1-12 (12 pages).

Wang, J.; Sui, J.; Karney, B., (2008). Incipient motion of noncohesive sediment under ice cover-an experimental study. J. Hydrody., 20 (1), 117-124 (8 pages).

White, K. D., (2003). Review of prediction methods for breakup for ice jams. Can. J. Civil Eng., 30 (1), 1-12 (12 pages).

\section{AUTHOR (S) BIOSKETCHES}

Wang, J., Ph.D., Full Professor, School of Civil Engineering, Hefei University of Technology, Anhui Province, 230009, China. Email: jun_wanghfut@126.com

Sui, J., Ph.D., Associate Professor, Environmental Engineering Program, University of Northern British Columbia 3333 University Way, Prince George, BC, V2N 4V9, Canada. Email: sui@unbc.ca

Guo, L., M.Sc., Graduate student, School of Civil Engineering, Hefei University of Technology, Anhui Province, 230009, China.

Email:yihu2003@sina.com

Karney, B. W., Ph.D., Full Professor, Department of Civil Engineering, University of Toronto, Toronto, Ontario, M5S 1A4, Canada.

Email: karney@ecf.utoronto.ca

Jüpner, R., Ph.D., Full Professor, Institute of Hydraulic Engineering and Water Management, Technical University of Kaiserslautern D-67663 Kaiserslautern; Germany. Email: juepner@rhrk.uni-kl.de

How to cite this article: (Harvard style)

Wang, J.; Sui, J.; Guo, L.; Karney, B. W.; Jüpner, R., (2010). Forecast of water level and ice jam thickness using the back propagation neural network and support vector machine methods. Int. J. Environ. Sci. Tech., 7 (2), 215-224. 